\title{
STATISTICS OF CANCER, 2020 IN INDIAN STATES: A REVIEW ON THE REPORT FROM NATIONAL CANCER REGISTRY PROGRAMME
}

\author{
SHAIK ASHA BEGUM ${ }^{1 *}$, JOSHNA RANI ${ }^{1}$, AHMADI BANU ${ }^{3}$, AVULA PAVANI ${ }^{2}$, VEENA YERUVA ${ }^{2}$ \\ ${ }^{1}$ Department of Pharmacy Practice, Institute of Pharmaceutical Technology, SPMVV, Tirupati, Andhra Pradesh, India. ${ }^{2}$ Department of \\ Pharmacology and Pharmacy Practice, Nirmala College of Pharmacy, Atmakur, Mangalagiri, Andhra Pradesh, India. ${ }^{3}$ Department of \\ Pharmcology, Vishnu Institute of Pharmaceutical Education and Research, Narsapur, Andhra Pradesh, India. Email: isk.asha86@gmail.com
}

Received: 27 March 2021, Revised and Accepted: 05 May 2021

\section{ABSTRACT}

The deliberate assortment of information on cancer growth was performed by different populace-based disease vaults (population-based cancer registries [PBCRs]) and clinic-based cancer growth libraries (hospital-based cancer registries [HBCRs]) across India under the National Cancer Registry Program-National Center for Disease Informatics and Research of Indian Council of Medical Research since 1982. This survey analyzed the malignant growth occurrence, designs, patterns, projections, and mortality from 28 PBCRs and furthermore the stage at introduction and kind of therapy of patients with disease from $58 \mathrm{HBCRs}(\mathrm{n}=667,666)$ from the pooled investigation for the composite time frame 2012-2016. Time patterns in cancer growth rate were created as yearly percent change from 16 PBCRs (those with at least 10 years of consistent great information accessible) utilizing Joinpoint relapse. Aizawl locale (269.4) and Papumpare region (219.8) had the most elevated age changed occurrence rates among guys and females, separately. The extended number of patients with disease in India is 1,392,179 for the year 2020, and the basic five driving destinations are cancer, lung, mouth, cervix uteri, and tongue. Patterns in disease frequency rate showed an expansion on the whole locales of cancer in both genders and were high in Kamrup Metropolitan (yearly percent change, 3.8\%; $<<0.05$ ). Most of the patients with cancer were analyzed at the privately progressed stage for cancer (57.0\%), cervix uteri (60.0\%), head and neck (66.6\%), and stomach (50.8\%) disease, while in cellular breakdown in the lungs, far off metastasis was dominating among guys (44.0\%) and females (47.6\%). This audit gives a system to surveying the status and patterns of cancer growth in India. It will manage proper help for activity to fortify endeavors to improve cancer growth avoidance and control to accomplish the public non-communicable illness targets and the reasonable advancement objectives.

Keywords: Canceristatistics, Breast cancer in india, Cancer registry programme, 2020 cancer report

(c) 2021 The Authors. Published by Innovare Academic Sciences Pvt Ltd. This is an open access article under the CC BY license (http://creativecommons.org/ licenses/by/4.0/) DOI: http://dx.doi.org/10.22159/ajpcr.2021v14i6.41616. Journal homepage: https://innovareacademics.in/journals/index.php/ajpcr

\section{INTRODUCTION}

Internationally, non-communicable infections (NCDs) accounted for $71 \%$ of absolute passing. In India, NCDs were estimated to represent $63 \%$, all things considered, and malignancy was one of the main sources (9\%) [1]. Cancer libraries are perceived as imperative segments of public malignant growth control programs [2]. Publications from created and non-industrial nations give refreshed data on malignancy event, patterns, and projections [3-7]. In India, the efficient assortment of information on disease has been performed since 1982 by the populace-based malignancy vaults (population-based cancer registries [PBCRs]) and emergency clinic-based disease vaults (hospital-based cancer registries [HBCRs]) under the National Cancer Registry Program (NCRP)National Center for Disease Informatics and Research (NCDIR) of the Indian Council of Medical Research (ICMR; ICMR-NCDIRNCRP), Bengaluru. NCRP initiated with the goal of producing solid information on the greatness and examples of disease. A few NCRP writes about malignancy from various libraries across India have been published $[8,9]$.

PBCRs give insights into the event and outhappen to malignancy in a topographically defined population. They additionally give the system to surveying the control of disease locally. HBCRs are worried about the chronicle of data on dead patients with disease found in a specific clinic and are chiefly utilized for auditing clinical execution and the medical clinic malignant growth program [10].

This article reports the malignancy rate, designs, time patterns, and mortality from 28 PBCRs for the composite time frame 2012-2016 across India under ICMR-NCDIR-NCRP. In addition, it covers the stage at introduction and sort of therapy got by patients with malignant growth from 58 HBCRs for the time frame 2012-2016 in India under the organization of NCRP. In light of appraisals from this period, the projection of patients with malignant growth in India for the year 2020 is additionally included.

\section{DATA FROM 28 PBCRS AND 58 HBCRS}

As of now, there are 36 PBCRs and 236 HBCRs enrolled under the ICMR-NCDIR-NCRP. In any case, this article includes information from 28 PBCRs and 58 HBCRs, which were finished with at any rate 1 year of good quality information. All neoplasms with a conduct code of 3 as defined by the International Classification of Diseases for Oncology, third Edition, and the International Statistical Classification of Diseases and Related Health Problems (tenth correction; ICD-10) were viewed as reportable and along these lines enlisted in NCRP [11]. Cancer enrollment is an unpredictable cycle. In India, malignant growth enrollment is dynamic wherein prepared vault staff goes to various sources (medical clinics, symptomatic research facilities, and crucial measurements divisions) for assortment of information on a standardized center form [10].

This is trailed by quality control checks, copy checks, coordinating with mortality cases, follow-up of death certificate notifications, and allocating demise certificate just (DCO). Patients with malignancy who were occupants in the enrollment territory for a base time of 1 year before the date of finding were remembered for the vault. Different disease information sources were followed for information collection [10]. Quality of the information was kept up per International Association of Cancer Registries/International Agency for Research on Cancer (IACR/IARC) norms [12,13]. 
Occurrence and mortality information were recovered from 28 PBCRs (metropolitan or country, or both) for the time frame 2012-2016. Malignancy trouble measures were determined as unrefined rate, age changed rate (AAR) per 100,000 populace utilizing world standard population [14], and combined danger (likelihood that an individual will be determined to have disease [0- to 74-year-mature age group] without any contending reason for death and accepting that the latest things beat the time frame). Time patterns in disease rate were produced as yearly percent change (APC) and considered genuinely significant (at $\mathrm{p}, 0.05$ ) from 16 PBCRs (with least of 10 years of information) utilizing the Joinpoint relapse program, 4.0.1 (National Cancer Institute) [15]. The long periods of information for pattern examination fluctuated (11-35 years) across the PBCRs, and there were six PBCRs with over 25 years of ceaseless information.

The nation was sorted into six geographic zones dependent on the area of the PBCRs: North (Delhi, Patiala), South (Hyderabad, Kollam, Thiruvananthapuram, Bengaluru, and Chennai), East (Kolkata), West (Ahmedabad metropolitan, Aurangabad, Osmanabad and Beed, Barshi rustic, Mumbai, and Pune), Central (Wardha, Bhopal, and Nagpur), and Northeast (NE; Manipur, Mizoram, Sikkim, Tripura, West Arunachal, Meghalaya, Nagaland, Pasighat, Cachar, Dibrugarh, and Kamrup metropolitan). Populace denominators were derived from the Census of India, directed by the Registrar General and Census Commissioner of India under the Ministry of Home Affairs, Government of India [16]. The evaluation populaces of 2001 and 2011 were utilized to calculate the post-censal populace gauges for the years 2012 and 2016 by 5 -year age gatherings and sex. For time pattern examination, the individual 1981, 1991, 2001, and 2011 censuses were taken as the base to appraise between or post-censal populace by 5 -year age gatherings and sex [17].

A normalized tolerant data structure for HBCRs under NCRP and the information assortment strategies have been clarified previously [18]. Newly determined and treated dead patients to have disease $(n=667,666)$ from 58 HBCRs (with at least 1 year of a total dataset) in 2012-2016 were pooled and are introduced as the overall extent of clinical stage and treatment. The stage/clinical degree of illness before therapy (avoids recently treated patients with disease) was classified into limited just, locoregional, inaccessible metastasis, and unknown [19]. The finish of arranged malignancy coordinated treatment after determination was classified as medical procedure, radiotherapy, fundamental treatment, and multimodality (blend of a medical procedure or potentially radiotherapy and additionally foundational treatment).

Great quality information records of infinitesimal verification (MV\%) above $75 \%$, DCO $\%$ underneath 20\%, other and unspecified locales ( $O$ and $\mathrm{U} \%$ ) beneath $15 \%$, and mortality-to-frequency proportion (M: I\%) were determined for each PBCR and likewise classified $[12,13]$. NCRP has created in-house programming (PBCR and HBCR Data Management) for information catch, quality checks, copies checks (deterministic and phonetic comparative sounding copy names), and mortality occurrence coordinating. The rundown of mistakes was sent back to vaults for clarifications and revised at each level. Frequency information for 2012-2016 was utilized as a source of perspective for projection of patients with malignancy in India until 2020 by sex and anatomic site (see Data Supplement for additional subtleties).

\section{CANCER INCIDENCE RATE ACCORDING TO NCRP}

Normal yearly number of patients for all locales of malignancy with occurrence rate, aggregate danger by sex, and death rate as indicated by various areas in India somewhere in the range of 2012 and 2016 is given in Table 1. PBCRs in the NE showed the most noteworthy frequency rate in both genders. It was seen that Aizawl area had the most elevated AAR (269.4) and mortality (152.7) rate among guys. One of each four guys in Aizawl locale, Papumpare area, East Khasi Hills region, and Kamrup metropolitan is probably going to create disease in the age gathering of 0-74 years. One of each four females in the Papumpare region and one of five females in Mizoram state are probably going to create malignancy in the age gathering of $0-74$ years.
On examination of AARs for all destinations of malignant growth (ICD10: C00-C97) across the populace among guys, Aizawl locale (269.4) had the most noteworthy AAR and was roughly double the AAR of Delhi PBCR (147.0). East Khasi Hills region of Meghalaya (227.9) had the second most elevated AAR, trailed by Kamrup metropolitan (213.0) and Mizoram PBCR (207.0). Among females, Papumpare region (219.8) had the most noteworthy AAR. In the remainder of the areas (barring NE), Delhi had most elevated AAR (147.0), trailed by Thiruvananthapuram region (137.8) among guys; Bengaluru (146.8) had most noteworthy AAR, trailed by Delhi (141.0) among females (Fig. 1).

East Khasi Hills region of Meghalaya had the most noteworthy relative extent of tumors related with the utilization of tobacco, with $70.4 \%$ and $46.5 \%$ for guys and females, separately. The higher extent of diseases related with utilization of tobacco was in the NE states, trailed by libraries in the West and Central districts (Fig. 2).

Among guys, lung, mouth, throat, and stomach were the most wellknown disease destinations. Among females, bosom disease, trailed by cervix uteri and ovary malignancy, was the most well-known locales across the PBCRs. Thyroid disease was the second most regular malignancy in the PBCRs of Thiruvananthapuram and Kollam, though cellular breakdown in the lungs was found in Manipur and Mizoram state. In the NE locale, the third most normal malignant growths were stomach and gallbladder (Data Supplement). The decadal changes in driving destinations of malignant growth from six more established PBCRs (Barshi rustic, Bengaluru, Bhopal, Chennai, Delhi, and Mumbai) were noticed for the first 10 and most recent 10 years of information (Data Supplement).

The general extent of patients as per clinical degree of infection at the hour of conclusion as found in the pooled information of 58 HBCRs for regular destinations of malignant growth showed that most of patients with disease were diagnosed as privately progressed/locoregional for bosom $(57.0 \%)$, cervix uteri $(60.0 \%)$, head and neck $(66.6 \%)$, and stomach $(50.8 \%)$ disease. Most of patients with cellular breakdown in the lungs were determined to have removed metastasis in guys $(44.0 \%)$ and females (47.6\%; Fig. 3). The relative supportive of bit of sorts of malignancy coordinated treatment got (just at the announcing emergency clinic) as indicated by clinical degree of sickness before therapy showed that multimodality was the first decision of therapy (locoregional, 79.5\%; restricted, 74.4\%; inaccessible metastasis, and 47.6\%; Data Supplement).

The assessed APC in malignancy AAR for chose anatomic locales of disease throughout the time span showed an increment in the occurrence pace of all destinations of malignant growth (12 PBCRs in guys and 13 PBCRs in females). There was a significant increment in the frequency pace of bosom malignant growth across all PBCRs throughout the long term, besides in Nagpur PBCR. There was a significant decline in the rate pace of cervical malignancy in 10 PBCRs, besides in Dibrugarh region and Pune. Cellular breakdown in the lungs showed a significant increment in 11 PBCRs among females.

Among 28 PBCRs, MV\% went between 77\% (Patiala) and 96.7\% (Hyderabad); DCO\% ran between 0.05\% (Osmanabad and Beed) and $19.4 \%$ (Patiala); 0 and U\% ran between 1.8\% (Hyderabad) and $13.0 \%$ (Patiala). M: I\% was high in Barshi country (67.2\%) trailed by Wardha (59.2\%) and Mumbai (56.0\%; Data Supplement).

The extended frequency of patients with malignancy in India among guys was 679,421 (94.1 per 100,000) and among females 712,758 (103.6 per 100,000 ) for the year 2020. One out of 68 guys (cellular breakdown in the lungs), one out of 29 females (bosom malignancy), and one of every nine Indians will create disease during their lifetime (0-74 years old). The extended five most basic malignant growths in 2020 for guys (lung, mouth, prostate, tongue, and stomach) establish $36 \%$, everything being equal, and for females (bosom, cervix uteri, ovary, corpus uteri, and lung) comprise $53 \%$, all things considered (Data Supplement). 
Table 1: Annual average no. of patients for all sites of cancer with incidence rate per 100,000, cumulative risk (0-74 age group), and mortality rate by sex and reporting year for 28 population-based cancer registries under National Cancer Registry Program

\begin{tabular}{|c|c|c|c|c|c|c|c|c|c|c|}
\hline \multirow[t]{3}{*}{ Registry (period of reference) } & \multicolumn{5}{|l|}{ Males } & \multicolumn{5}{|c|}{ Females } \\
\hline & \multicolumn{4}{|c|}{ Incidence } & \multirow{2}{*}{$\begin{array}{l}\text { Mortality } \\
\text { AAMR }\end{array}$} & \multicolumn{4}{|c|}{ Incidence } & \multirow{2}{*}{$\begin{array}{l}\text { Mortality } \\
\text { AAMR }\end{array}$} \\
\hline & No. & CR & AAR & Cum Risk & & No. & CR & AAR & Cum Risk & \\
\hline Delhi (2012-14) & 10,344 & 112.3 & 147.0 & 1 in 6 & 22.2 & 9,688 & 119.6 & 141.0 & 1 in 7 & 17.8 \\
\hline Patiala district (2012-16) & 1,079 & 101.6 & 108.2 & 1 in 9 & 32.7 & 1,215 & 127.7 & 124.6 & 1 in 8 & 30.1 \\
\hline Hyderabad district (2014-16) & 1714 & 84.2 & 101.6 & 1 in 9 & 15.5 & 2151 & 109.8 & 136.0 & 1 in 7 & 12.5 \\
\hline Kollam district $(2012-16)$ & 1986 & 159.4 & 127.7 & 1 in 7 & 66.5 & 1956 & 139.1 & 107.1 & 1 in 9 & 38.3 \\
\hline Thiruvananthapuram district (2012-16) & 2701 & 170.4 & 137.8 & 1 in 7 & 57.7 & 2865 & 164.8 & 127.3 & 1 in 8 & 39.5 \\
\hline Bangalore $(2012-14)$ & 4407 & 96.8 & 122.1 & 1 in 7 & 42.6 & 5276 & 125.1 & 146.8 & 1 in 6 & 41.5 \\
\hline Chennai (2012-16) & 2894 & 121.8 & 119.9 & 1 in 8 & 35.7 & 3361 & 141.4 & 132.8 & 1 in 7 & 28.8 \\
\hline Kolkata (2012-15) & 2547 & 109.9 & 91.2 & 1 in 10 & 37.9 & 2288 & 105.9 & 89.2 & 1 in 11 & 32.1 \\
\hline Ahmedabad urban (2012-16) & 2916 & 89.1 & 98.3 & 1 in 9 & 27.0 & 2205 & 74.7 & 76.7 & 1 in 12 & 16.9 \\
\hline Aurangabad (2012-16) & 385 & 56.6 & 70.9 & 1 in 13 & 13.5 & 400 & 62.9 & 75.1 & 1 in 12 & 8.5 \\
\hline Osmanabad and Beed (2012-15) & 909 & 39.3 & 39.5 & 1 in 23 & 10.3 & 1117 & 52.8 & 49.4 & 1 in 19 & 10.4 \\
\hline Barshi Rural (2012-16) & 145 & 53.9 & 50.6 & 1 in 17 & 35.0 & 163 & 67.2 & 61.0 & 1 in 15 & 36.1 \\
\hline Mumbai (2012-15) & 6564 & 97.3 & 108.4 & 1 in 9 & 66.0 & 6865 & 117.6 & 116.2 & 1 in 8 & 61.4 \\
\hline Pune (2012-16) & 1937 & 67.5 & 83.0 & 1 in 11 & 45.3 & 2164 & 83.3 & 94.0 & 1 in 10 & 35.3 \\
\hline Wardha district (2012-16) & 478 & 70.4 & 64.5 & 1 in 14 & 42.3 & 507 & 78.7 & 69.9 & 1 in 14 & 37.1 \\
\hline Bhopal (2012-15) & 892 & 83.3 & 101.0 & 1 in 9 & 38.3 & 897 & 93.4 & 106.9 & 1 in 8 & 30.9 \\
\hline Nagpur (2012-16) & 1190 & 89.0 & 91.1 & 1 in 10 & 21.3 & 1.209 & 93.1 & 89.8 & 1 in 11 & 17.7 \\
\hline Manipur state (2012-16) & 740 & 47.0 & 62.8 & 1 in 14 & 20.5 & 900 & 57.8 & 71.1 & 1 in 12 & 17.3 \\
\hline Mizoram state (2012-16) & 865 & 146.1 & 207.0 & 1 in 5 & 121.4 & 747 & 127.5 & 172.3 & 1 in 5 & 76.4 \\
\hline
\end{tabular}

Reporting year data given in parentheses; Meghalaya covers East Khasi Hills, West Khasi Hills, Jaintia Hills, and Ri Bhoi districts; Nagaland covers Kohima and Dimapur districts; Pasighat covers East Siang and Upper Siang; West Arunachal covers Tawang, West Kameng, East Kameng, Upper Subansiri, Lower Subansiri, Kurung Kumey, Papumpare, and West Siang districts. Abbreviations: AAMR, age-adjusted mortality rate per 100,000; AAR: Age-adjusted rate per 100,000; CR: Crude rate per 100,000; cum risk: cu

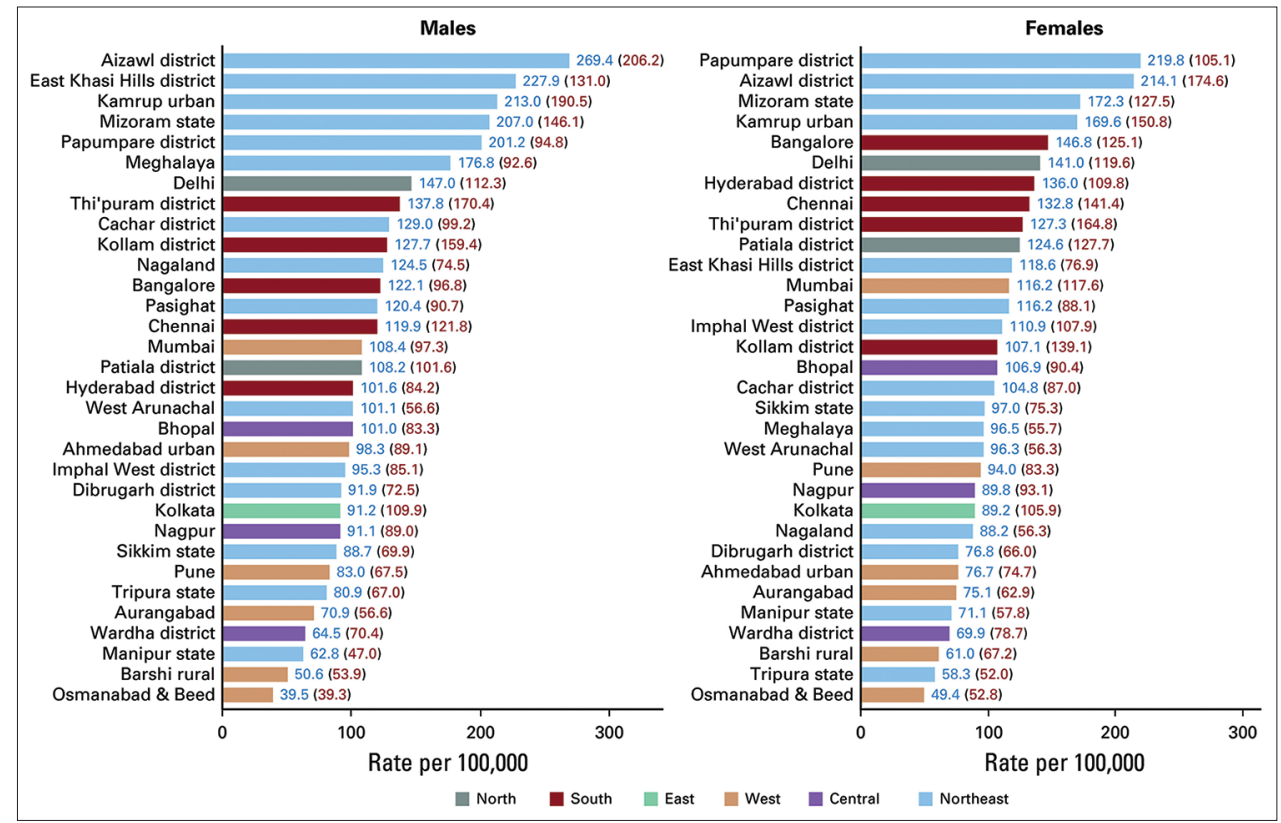

Fig.1: Comparison of all age-related cancer risk sites (AARs) for all human-based cancer registers, 2012-2016 (International Statistical Classification of Diseases and Related Health Problems, 10 $^{\text {th }}$ revision: C00-C97)

Compared to the AARs of all cancer sites (CD10: C00C97) everywhere among men, the Aizawl region (269.4) had the highest AAR and almost double the AAR Delhi PBCR (147.0) The East Khasi Hills region of Meghalaya (227.9) had the second highest AAR followed by Kamrupiurban (213.0) and Mizoram PBCR (207.0). Among women, the Papumpare region (219.8) had the highest AAR. In other regions (excluding NE), Delhi had the highest AAR (147.0), followed by the Thiruvanathapuram region (137.8) among men;Bengaluru (146.8) had the highest AAR followed by Delhi (141.0) among women (Fig. 1).

The East Khasi Hills district in Meghalaya had the highest rates of cancer related cancer, at $70.4 \%$ and $46.5 \%$ of men and women, respectively. The highest rates of cancer related cancer were in the NE provinces followed by registrars in the Western and Central regions (Fig. 2).
Relative number (\%) of patients according to disease at the clinic, in 2012-2016 (average [\%] may not be 100\% due to collection).

\section{OVERALL CANCER INCIDENCE RATES IN INDIA STATE WISE}

India shows heterogeneity in disease. The occurrence paces of Aizawl area were seen to be multiple times and multiple times that of Osmanabad and Beed region PBCRs in guys and females, individually. The most elevated malignant growth frequency rate was seen in the $\mathrm{NE}$ district (six PBCRs for guys and four PBCRs for females) than different territories in the country. The main destinations of malignant growth in the NE area were nasopharynx, hypopharynx, throat, stomach, liver, gallbladder, larynx, lung, bosom, and cervix uteri. The NE locale needs required foundation regarding specific treatment offices, HR, as seen 


\begin{tabular}{|c|c|c|c|c|}
\hline & & North & & \\
\hline$(46.3,62.1)$ & 41.2 & Delhi & 12.4 & $(18.5,14.8)$ \\
\hline \multirow[t]{2}{*}{$(36.9,39.9)$} & 364 & Patiala district & 13.1 & $(16.6,16.8)$ \\
\hline & & South & & \\
\hline$(67.7,52.9)$ & 42.5 & Kollam district & 12.4 & $(12.4,17.2)$ \\
\hline$(35.6,42.6)$ & 42.2 & Hyderabad district & 13.5 & $(19.1,14.8)$ \\
\hline$(49.5,47.6)$ & 40.6 & Chennai & 13.6 & $(18.1,19.2)$ \\
\hline$(62.0,49.0)$ & 36.1 & Thi'puram district & 10.1 & $(12.5,16.8)$ \\
\hline \multirow[t]{2}{*}{$(29.7,38.7)$} & 33.4 & Bangalore & 14.2 & $(20.1,16.3)$ \\
\hline & & East & & \\
\hline \multirow[t]{2}{*}{$(51.3,42.3)$} & 46.7 & Kolkata & 15.4 & $(13.7,16.3)$ \\
\hline & & West & & \\
\hline$(50.0,54.3)$ & 56.1 & Ahmedabad urban & 18.6 & $(14.5,13.9)$ \\
\hline$(31.6,40.0)$ & 55.8 & Aurangabad & 16.3 & $(12.7,10.2)$ \\
\hline$(16.1,16.5)$ & 41.0 & Osmanabad \& Beed & 12.7 & $(6.1,6.7)$ \\
\hline$(26.4,32.5)$ & 39.1 & Pune & 15.2 & $(14.6,12.7)$ \\
\hline$(37.7,41.8)$ & 38.7 & Mumbai & 15.6 & $(18.2,18.4)$ \\
\hline \multirow[t]{2}{*}{$(18.5,17.3)$} & 34.3 & Barshi rural & 14.9 & $(8.6,10.0)$ \\
\hline & & Central & & \\
\hline$(45.8,55.3)$ & 549 & Bhopal & 17.7 & $(19.6,16.0)$ \\
\hline$(41.1,41.5)$ & 462 & Nagpur & 17.3 & $(15.8,16.1)$ \\
\hline$(29.9,27.0)$ & 424 & Wardha district & 18.6 & $(12.7,14.6)$ \\
\hline$(92.2,161.3)$ & 70.4 & $\begin{array}{c}\text { Northeast } \\
\text { East Khasi Hills } \\
\text { district }\end{array}$ & 46.5 & $(58.1,35.8)$ \\
\hline$(61.9,119.7)$ & 669 & Meghalaya & 43.1 & $(44.6,24.0)$ \\
\hline$(53.6,71.3)$ & 540 & Cachar district & 23.4 & $(26.9,20.4)$ \\
\hline$(34.9,43.2)$ & 52.1 & Tripura state & 21.1 & $(13.0,11.0)$ \\
\hline$(37.6,48.9)$ & 51.8 & Dibrugarh district & 21.8 & $(18.2,14.4)$ \\
\hline$(98.2,110.2)$ & 51.6 & Kamrup urban & 23.5 & $(43.2,35.4)$ \\
\hline$(97.3,127.1)$ & 47.2 & Aizawl district & 24.4 & $(56.9,42.6)$ \\
\hline$(63.2,89.3)$ & 43.3 & Mizoram state & 22.1 & $(42.3,28.1)$ \\
\hline$(29.3,51.1)$ & 39.3 & Nagaland & 11.5 & $(12.5,6.5)$ \\
\hline$(31.7,36.8)$ & 37.3 & Imphal West district & 19.1 & $(22.2,20.6)$ \\
\hline$(17.3,24.7)$ & 36.8 & Manipur state & 19.5 & $(15.8,11.3)$ \\
\hline$(22.9,29.5)$ & 32.8 & Sikkim state & 18.2 & $(19.2,13.7)$ \\
\hline$(28.9,67.7)$ & 30.5 & Papumpare district & 14.4 & $(43.6,15.1)$ \\
\hline$(26.3,36.1)$ & 29.0 & Pasighat & 10.9 & $(14.5,9.6)$ \\
\hline \multirow[t]{2}{*}{$(13.9,26.6)$} & 24.5 & West Arunachal & 11.1 & $(13.7,6.3)$ \\
\hline & Males (\%) & & Females (\%) & \\
\hline
\end{tabular}

Fig. 2: Sites of cancer associated with the use of tobacco (\%), 2012-2016. Crude rate in red and age-adjusted rates in blue are given in parentheses. Sites of cancer associated with the use of tobacco, anatomic sites (International Statistical Classification of Diseases and Related Health Problems, 10th revision codes), lip (C00); tongue (C01-C02); mouth (C03-C06); pharynx (C10 and C12-C14); esophagus (C15); larynx (C32); lung (C33- C34); urinary bladder (C67). Thi'puram district, Thiruvananthapuram district.

by the low 5-year endurance of bosom, cervix, and head and neck malignant growth contrasted and rest of India. A considerable extent of patients with disease from the NE area is going external the NE for therapy and malignant growth care [20,21]. Local social components and way of life decisions may have added to the heterogeneity in malignancy frequency design and differences in India, as was seen in Thailand [7].

Lung (nine PBCRs), mouth (nine PBCRs), throat (five PBCRs), stomach (four PBCRs), and nasopharynx (one PBCR) diseases were the most widely recognized tumors in men. Cellular breakdown in the lungs was the main site in metropolitan urban communities and the southern locale, though mouth disease was the main site in the West and Central districts. Cellular breakdown in the lungs and oral/mouth malignancy was the most widely recognized tumors among guys in the Indian subcontinent [22]. Cancers of the throat, stomach, and nasopharynx were the main destinations in the NE district of India. Here, the malignant growth frequency design is different from the remainder of India. There are likenesses in the malignancy rate design with the Southeast Asian region [23]. Overall, these findings on examples of disease were like recently distributed reports under NCRP [8].

Malignant growth of the bosom (19 PBCRs) and cervix uteri (seven PBCRs) was the most widely recognized tumors in ladies. The most noteworthy weight of bosom disease was seen in metropolitan urban communities. There is an expansion in the pattern of occurrence of 


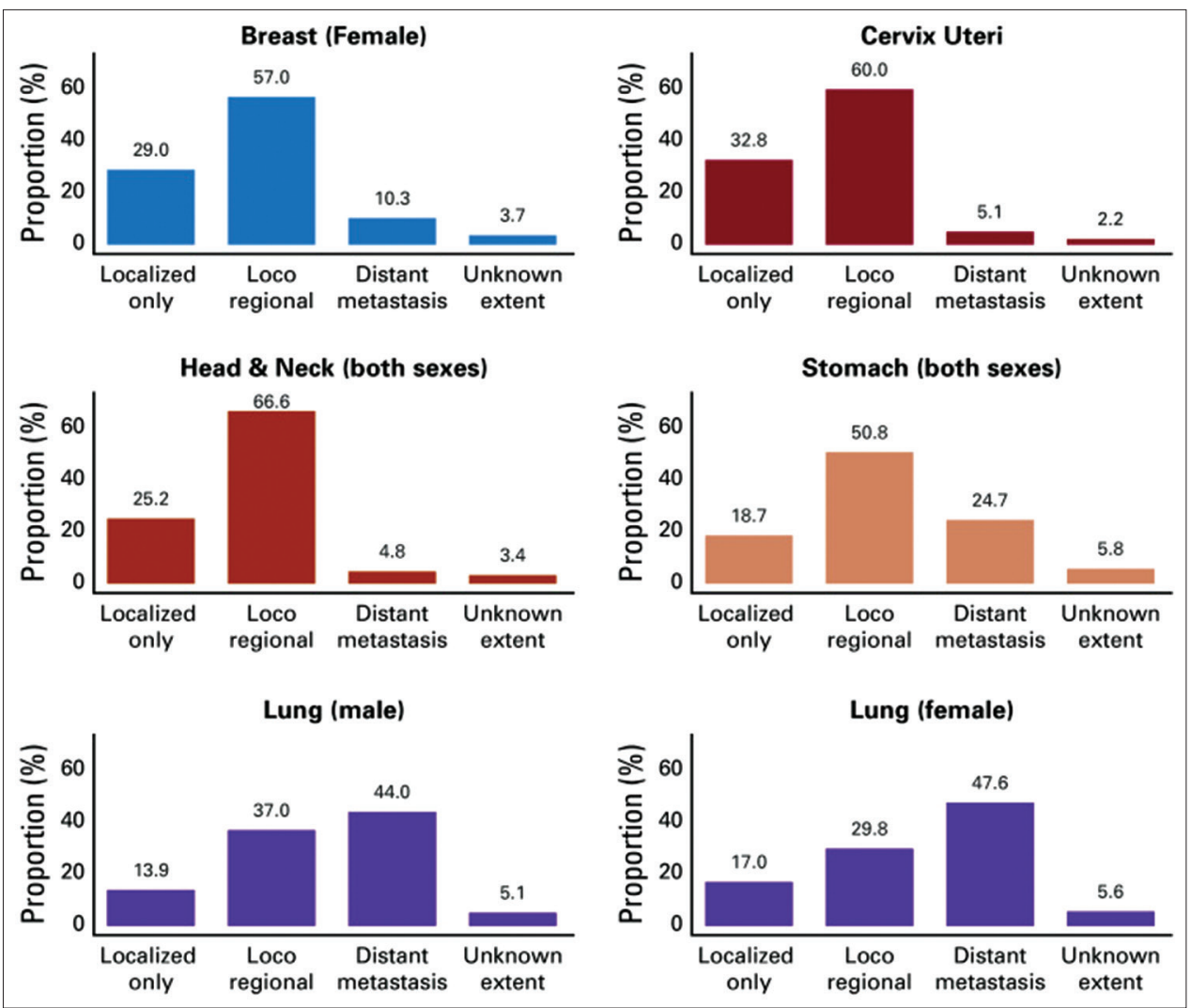

Fig. 3: Relative proportion (\%) of patients according to clinical extent of disease, 2012-2016 (proportion [\%] may not total 100\% because of rounding)

bosom malignant growth, though cervix uteri disease is on the decline. A consistent expansion in bosom malignant growth in a large portion of the PBCRs, including fresher PBCRs, represents an extraordinary wellbeing challenge to ladies in India [24]. At present, bosom disease and cervix uteri are the main locales of malignant growth among ladies in India, representing a significant general medical condition that needs significant contribution from different well-being and different offices to tackle [25]. A multidisciplinary way to deal with bosom malignancy, including mindfulness programs, preventive measures, screening programs for early recognition, and benefit capacity of therapy offices, is imperative for decreasing both frequency and mortality of malignant growth in Indian women [26].

The rate pace of thyroid malignant growth among ladies is expanding, and it is generally normal in the areas of Thiruvananthapuram and Kollam in Kerala. The high weight of thyroid disease in Kerala could be expected to overdiagnosis [27], as was noticed even in big league salary and low and center pay countries [28]. AAR in Barshi country is very nearly $33 \%$ of metropolitan PBCRs (guys, 50.6 v 147.0; females, $61.0 \mathrm{v}$ 146.8), and the increment in APC was less contrasted and metropolitan PBCRs.

There are tumors of a few anatomic locales known to be related with the utilization of tobacco [29]. Based on PBCR information, just about $33 \%$ of the malignancies were known to be associated with the utilization of tobacco in India. India state-level illness trouble activity malignant growth teammates assessed that tobacco use was the most noteworthy contributing danger factor for disease in India. In India, cellular breakdown in the lungs can be credited to tobacco use and air contamination, which are the main danger factors [30]. Approximately $70 \%$ of malignant growths in India were conceivably preventable through modifiable danger factors [31].

Since it is difficult to get data on the clinical degree of illness and therapy from PBCRs, the clinic information base was utilized for such analysis [10]. Most of bosom and cervix uteri malignancies were analyzed at a privately progressed stage. Chemoradiation was the most widely recognized kind of therapy of malignancy cervix uteri. A multi-institutional examination from India on cervix malignant growth showed significantly preferred endurance with chemoradiation overradiation alone in the privately progressed stage [18]. An investigation from Chennai showed that simultaneous chemoradiation for privately progressed cervical disease brought about the best infection free survival [32]. About $66 \%$ of the patients with malignant growth were analyzed at the locoregional stage for head-and-neck tumors from HBCRs. Like that, a low extent of patients with head-and-neck malignancy introduced in the beginning phase, and a high extent (88.1\%) was seen in Uttarakhand [33]. Multimethodology was the most well-known therapy given for bosom and head-and-neck malignancies. A multi-institutional investigation assessed that $65 \%$ of new head-and-neck tumors with privately progressed infection did not get the benefit of ideal treatment, bringing about poor survival [34].

Short of what one-fifth of lung and stomach tumors were analyzed as confined as it were. Fundamental treatment was the most well-known kind of therapy given for lung and stomach malignancy. A past report on HBCR results showed comparable findings. An emergency clinicbased examination from North India showed that $90 \%$ of patients with cellular breakdown in the lungs were diagnosed at a high-level phase of the infection, and there was a postponement in symptomatic assessment and treatment [35]. Creating malignancy mindfulness, forestalling hazard factors, and improving admittance to mind among individuals would bring about downstaging of disease.

The proportion of legitimacy, MV\%, was above $77 \%$ for all the PBCRs. Changing examples of DCO\% and M: I\% were observed among PBCRs which were subject to the nature of death enlistment and certification [13]. Efforts to improve the quality are consistently in progress. In certain vaults, low DCO\% (1\%) is because of nonavailability of all-cause mortality information and inadequate/off-base certification of reason for death. A few vaults had an efficient follow back procedure by house visit/telephone. Information from PBCRs were 
regularly distributed in progressive volumes of Cancer Incidence in Five Continents (CI-5) by the WHO-IACR/IARC. The frequency information from 15 PBCRs under NCRP (India) was distributed in Cancer Incidence in Five Continents, Volume XI, by the WHO-IACR/IARC [36-38]

The extended occurrence of patients with malignant growth is higher for females $(712,758)$ than guys $(679,421)$ for the year 2020 . The projected public malignant growth rate trouble in 2020 will be 98.7 per 100,000 populace $(1,392,179$ patients) as a traditionalist gauge. It is expected that the noticed pace of 2012-2016 will stay unaltered until 2020. The time pattern in rate was not used to dodge vulnerability in the projection for a crowded nation like India. NCRP has assessed a marginally higher number of patients with malignant growth contrasted and IACR/IARC and GLOBOCAN for all locales of disease in 2018. This might be a result of a distinction in system and utilization of ongoing information $(1,392,179 \mathrm{v} 1,157,294)$ [22]. This is the first such endeavor in the country and will be additionally refreshed on accessibility of the following informational index and enumeration data. The influencing factors, for example, hazard factors/conduct, case finding strategy, screening program, and improved strategies for recognizing patients with cancer growth, are probably going to influence the extended number of patients.

PBCRs in this examination covered 100 million normal yearly individual years, representing inclusion near $10 \%$ of the populace in India. Cancer enlistment in India faces a few difficulties since it's anything but a notifiable sickness, presenting difficulties to information collection [39-42]. The mortality enrollment framework has a few holes, including inadequate and off-base certification of reason for death $[43,44]$. Registering through latent notification by medical services suppliers to report disease event in India would improve the inclusion with restricted assets. Connecting of malignant growth vault information with Ayushman Bharat [45], mortality data sets, and the Hospital Information System would improve disease registration, follow-up, and result information.

This examination gives a structure to evaluating the status and patterns of cancer growth in India. This will direct suitable help for activity to reinforce endeavors to improve cancer growth avoidance and control to accomplish the national NCD targets and the practical advancement goals $[46,47]$. The information additionally give prompts key exploration questions.

\section{ACKNOWLEDGMENT}

The authors recognize the commitment of the 28 populace-based cancer vaults and 58 emergency clinic-based disease libraries under the NCRP, which contributed information, and Research Area Panel Expert Group on Cancer.

\section{AUTHORS' CONTRIBUTIONS}

Dr. S. Joshna Rani has gathered updated cancer registry program data. Dr. Ahmadi Banu has compiled the relevant information. Miss Veena and Miss Pavani have prepared the chart relevant data. The whole data have been assembled by the corresponding author.

\section{AUTHORS' FUNDING}

Not applicable.

\section{REFERENCES}

1. World Health Organization. World Health Statistics 2019: Monitoring Health for the SDGs. Geneva, Switzerland: World Health Organization; 2018.

2. Parkin DM. The evolution of the population-based cancer registry. Nat Rev Cancer 2006;6:603-12.

3. Nandakumar A, Gupta PC, Gangadharan P, Visweswara RN, Parkin DM. Geographic pathology revisited: Development of an atlas of cancer in India. Int J Cancer 2005;116:740-54.

4. Swaminathan R, Selvakumaran R, Esmy PO, Sampath P, Ferlay J,
Jissa V, et al. Cancer pattern and survival in a rural district in South India. Cancer Epidemiol 2009;33:325-31

5. Jemal A, Ward EM, Johnson CJ, Cronin KA, Ma J, Ryerson B, et al. Annual report to the nation on the status of cancer, 1975-2014, featuring survival. J Natl Cancer Inst 2017;109:djx030.

6. de Camargo B, de Oliveira Santos M, Rebelo MS, de Souza Reis R, Ferman S, Noronha CP, et al. Cancer incidence among children and adolescents in Brazil: First report of 14 population-based cancer registries. Int J Cancer 2010;126:715-20

7. Pongnikorn D, Daoprasert K, Waisri N, Laversanne M, Bray F. Cancer incidence in Northern Thailand: Results from six population-based cancer registries 1993-2012. Int J Cancer 2018;142:1767-75.

8. National Centre for Disease Informatics and Research: Consolidated Report of Population Based Cancer Registries, 2006-2008, 2009-2011, 2012-2014 Bengaluru, India, National Cancer Registry Programme (NCRP-ICMR). Available from: https://www.ncdirindia.org/Reports. aspx.

9. National Centre for Disease Informatics and Research: Time Trends in Cancer Incidence Rates, 1982-2010, Bangalore: National Cancer Registry Programme (NCRP-ICMR), 2013. Available from: https:// www.ncdirindia.org/All_Reports/TREND_REPORT_1982_2010.

10. Jensen OM, Parkin DM, MacLennan R, Muir CS, Skeet R, editors. Cancer Registration: Principles and Methods. Lyon, France: IARC Scientific Publications; 1991

11. World Health Organization. International Statistical Classification of Diseases and Related Health Problems. Geneva, Switzerland: World Health Organization; 1994.

12. Bray F, Parkin DM. Evaluation of data quality in the cancer registry: Principles and methods. Part I: Comparability, validity and timeliness. Eur J Cancer 2009;45:747-55.

13. Parkin DM, Bray F. Evaluation of data quality in the cancer registry: Principles and methods Part II. Completeness. Eur J Cancer 2009; 45:756-64

14. Segi M. Cancer Mortality for Selected Sites in 24 Countries 1950-1957. Sendai, Japan: The Department of Public Health, Tohoku University School of Medicine; 1960

15. National Cancer Institute. Join Point Regression Program, Version 4.0.1. Statistical Research and Application Branch, National Cancer Institute; 2013. Available from: https://www.surveillance.cancer.gov/ joinpoint.

16. Census of India: Registrar General of India, Socio Cultural Tables, C14, Population by Five Year Age Group, by Residence and Sex, New Delhi, 2001-2011. Available from: http://www.censusindia.gov.in.

17. Takiar R, Shobana B. Cancer incidence rates and the problem of denominators a new approach in Indian cancer registries. Asian Pac J Cancer Prev 2009; 10:123-6.

18. Nandakumar A, Rath GK, Kataki AC, Bapsy PP, Gupta PC, Gangadharan $\mathrm{P}$, et al. Concurrent chemoradiation for cancer of the cervix: Results of a multi-institutional study from the setting of a developing country (India) J Glob Oncol 2015;1:11-22.

19. Edge SB. AJCC Cancer Staging Manual. $7^{\text {th }}$ ed. New York: Springer; 2010.

20. National Centre for Disease Informatics and Research: Report on Cancer Burden in North Eastern States of India. Bengaluru, India: National Cancer Registry Programme (NCRP-ICMR). Available from: http://www.ncdirindia.org.

21. Ngaihte P, Zomawia E, Kaushik I. Cancer in the North East India: Where we are and what needs to be done? Indian J Public Health 2019;63:251-3.

22. Bray F, Ferlay J, Soerjomataram I, Siegel RL, Torre LA, Jemal A. Global cancer statistics 2018: GLOBOCAN estimates of incidence and mortality worldwide for 36 cancers in 185 countries. CA Cancer J Clin 2018;68:394-424

23. Sharma JD, Kalit M, Nirmolia T, Saikia SP, Sharma A, Barman D. Cancer: Scenario and relationship of different geographical areas of the globe with special reference to North East-India. Asian Pac J Cancer Prev 2014;15:3721-9.

24. Chaturvedi M, Vaitheeswaran K, Satishkumar K, Das P, Stephen S, Nandakumar A. Time trends in breast cancer among Indian women population: An analysis of population based cancer registry data. Indian J Surg Oncol 2015;6:427-34

25. Takiar R. Status of breast and cervix cancer in selected registries of India. Ann Womens Health 2018;2:1012.

26. Malvia S, Bagadi SA, Dubey US, Saxena S. Epidemiology of breast cancer in Indian women. Asia Pac J Clin Oncol 2017;13:289-95

27. Mathew IE, Mathew A. Rising thyroid cancer incidence in Southern India: An epidemic of overdiagnosis? J Endocr Soc 2017;1:480-7. 
28. Lortet-Tieulent J, Franceschi S, Dal Maso L, Vaccarella S. Thyroid cancer "epidemic" also occurs in low- and middle-income countries. Int J Cancer 2019;144:2082-7.

29. World Health Organization. Overall Evaluations of Carcinogenicity: An Updating of IARC Monographs. Vol. 1-42. Lyon, France: IARC, World Health Organization; 1987.

30. India State-Level Disease Burden Initiative Cancer Collaborators. The burden of cancers and their variations across the states of India: The global burden of disease study 1990-2016. Lancet Oncol 2018;19:1289-306.

31. Gandhi AK, Kumar P, Bhandari M, Devnani B, Rath GK. Burden of preventable cancers in India: Time to strike the cancer epidemic. J Egypt Natl Canc Inst 2017;29:11-8.

32. Shanta V, Selvaluxmy G, Swaminathan R, Shanthi P. Evolution in the management of locally advanced cervical cancer: The experience of cancer institute (WIA), Chennai, India. Asian Pac J Cancer Prev 2010;11:1091-8.

33. Pandey KC, Revannasiddaiah S, Pant NK, Bhatt HC. Stage-wise presentation of non-metastatic head and neck cancer: An analysis of patients from the Kumaon hills of India. Asian Pac J Cancer Prev 2014;15:4957-61.

34. Nandakumar A, Rath GK, Kataki AC, Sharma JD, Das K. Survival in head and neck cancers: Results of a multi-institution study. Asian Pac J Cancer Prev. 2016;17:1745-54

35. Chandra S, Mohan A, Guleria R, Singh V, Yadav P. Delays during the diagnostic evaluation and treatment of lung cancer. Asian Pac J Cancer Prev 2009; 10:453-6.

36. Curado MP, Edwards B, Shin HR, Storm H, Ferlay J, Heanue M, editors. Cancer Incidence in Five Continents. Vol. 9. Lyon, France: IARC Scientific Publications; 2007.

37. Forman D, Bray F, Brewster DH, Mbalawa CG, Kohler B, Piñeros M, editors. Cancer Incidence in Five Continents. Vol. 10. Lyon, France:
IARC Scientific Publications; 2014.

38. Bray F, Colombet M, Mery L, Piñeros M, Znaor A, Zanetti R, editors. Cancer Incidence in Five Continents. Vol. 11. Lyon, France: IARC Scientific Publications; 2017.

39. Bray F, Znaor A, Cueva P, Korir A, Swaminathan R, Ullrich A, editors. Planning and Developing Population-Based Cancer Registration in Low and Middle-Income Settings. Lyon, France: IARC Technical Publication; 2014.

40. Dhar M. A critical review of evolution of cancer registration in India. J Tumor Med Prev 2018;2:555594.

41. Sahoo SS, Verma M, Parija PP. An overview of cancer registration in India: Present status and future challenges. Oncol J India 2018;2:86-9.

42. Behera P, Patro BK. Population based cancer registry of India the challenges and opportunities. Asian Pac J Cancer Prev 2018;19:2885-9.

43. Kakkar R, Aggarwal P. Civil registration and sample registration system: Challenges and initiatives. SRHU Med J 2017;1:47-9.

44. ORGI Report on Medical Certification of Cause of Death (MCCD) 2017, India, Office of the Registrar General, Ministry of Home Affairs. Vital Stat (Ott Annu Ed); 2017. Available from: https://www.censusindia. gov.in/2011-Documents/mccd_Report1/MCCD_Report-2017.pdf.

45. National Health Authority: Ayushman Bharat Pradhan Mantri Jan Arogya Yojana. National Health Authority, Government of India. Available from: http://www.pmjay.gov.in.

46. World Health Organization. NCD Global Monitoring Framework. Available from: https://www.who.int/nmh/global monitoring framework/2013-11-06-who-dc-c268-whp-gap-ncds-techdoc-def3. pdf?ua $=1$.

47. United Nations: Transforming our World: The 2030 Agenda for Sustainable Development. Available from: https://www. sustainabledevelopment.un.org/content/documents/21252030\%20 Agenda $\% 20$ for $\% 20$ Sustainable\%20Development $\% 20$ web.pdf. 